\title{
Determination of lung volumes from chest films
}

\author{
J. O'S HEA, N. L. LAPP,A.D. RUSSAKOFF, R. REGER, \\ and W. K. C. MOR G A N \\ Appalachian Laboratory for Occupational Respiratory Diseases, U.S. Public Health Service, \\ Bureau of Occupational Safety and Health, and Department of Medicine, \\ West Virginia University Medical Center, Morgantown, West Virginia
}

The results obtained from two radiological methods of determining total lung capacity (TLC) (Kovach's parabo.oid and Barnhard's ellipsoid) were compared with those obtained with the body plethysmograph. Determinations of TLC were made in four groups of subjects: group 1 consisted of 26 miners most of whom had simple pneumoconiosis ; group 2 consisted of 12 normal subjects ; group 3 consisted of eight subjects who had a variety of chest disease, but with no demonstrable parenchymal or pleural opacification; and group 4 consisted of 19 subjects with misce!laneous diseases, all showing demonstrable infiltration or opacification.

The values obtained by the method of Kovach and his colleagues often differed markedly from the plethysmographic determinations, and it became apparent that this method was not sufficiently accurate. On the other hand, the technique of Barnhard and his colleagues gave results that were essentially similar to, and as far as we can say interchangeable with, those obtained by the body plethysmograph in groups 1,2 , and 3 . In subjects with marked pulmonary opacification or infiltration, the disparity between Barnhard's method and the plethysmograph tended to be more sizeable. It was concluded that Barnhard's method for determining total lung capacity is accurate and could be applied to epidemiological surveys.

The first attempt to measure the residual volume (RV) of the lungs was made by Davy in 1799, and described in 1839. With one exception, the methods introduced since then all require expensive equipment and most are technically difficult. These remarks are particularly applicable to the three most widely used methods at the present time, viz., closed circuit helium equilibration, the open circuit nitrogen washout and the body plethysmograph. There have been several claims that total lung capacity (TLC) can be ascertained with a reasonable degree of accuracy from a chest film, a method that has much to offer by virtue of its simplicity and inexpensiveness.

The first attempt to determine lung volumes from a chest radiograph was made by Hurtado and Fray (1933). These workers combined planimetry with external measurements of chest size. Refinements of this technique were introduced by other workers (Aslett, Hart, and McMichael, 1939), though none was entirely satisfactory since all involved the use of rather arbitrary correction factors. Kovach, Avedian, Morales, and Poulos (1956) suggested that 'the whole thoracic cage be treated as a paraboloid of revolution' and they derived a method of determining the TLC from a single postero-anterior (PA) film taken at full inspiration. Later, Barnhard, Pierce, Joyce, and Bates (1960) introduced another technique which utilized both PA and lateral films and in which the lungs were considered as a series of elliptical cylindroids. Since it seems fairly well accepted that Kovach's and Barnhard's methods are to be preferred to those of earlier workers, we decided to conduct a study to determine the accuracy of their methods and to compare the results obtained with them to those obtained by standard techniques in the hope that, should one of the radio logical methods prove to be satisfactory, then it could be used in epidemiological studies.

\section{MATERIALS AND METHODS}

Four groups of subjects were included in the study:

1. twenty-six coal miners, of whom 24 had definite simple pneumoconiosis, while the films of the remaining 2 were read as suspicious ( $\mathrm{Z}$ in ILO classification) (1959) ;

2. twelve normal subjects ;

3. eight subjects with miscellaneous chest diseases who showed no pulmonary infiltration, viz., asthmatics and emphysematous patients ;

4. nineteen subjects with a variety of chest diseases all of whom had demonstrable infiltration present on 
the chest films. Included in this group were subjects with inactive tuberculosis, progressive massive fibrosis, etc. The extent of the infiltrate present in the lung fields was graded from 1 to 5 . If an area equivalent to one-fifth of one lung was opaque, this was graded as 1 ; if the infiltration or opacification was extensive enough to fill two-fifths of a lung field, this was graded 2 ; and so on so that if the infiltrate or opacification completely filled one lung field, this was graded 5.

The degree of obstructive and restrictive impairment present in the miners and other patients was assessed according to the criteria of Gaensler and Wright (1966).

Four methods were used in the determination of lung volumes:

1. by means of a body plethysmograph using the technique of DuBois, Botelho, Bedell, Marshall, and Comroe (1956);

2. by nitrogen washout as described by Darling, Cournand, and Richards (1940) ;

3. radiographically by means of:

(a) the paraboloidal method of Kovach et al. (1956) ;

This requires a standing $\mathbf{P A}$ chest film taken at maximal inspiration.

Kovach and his colleagues chose to regard the thoracic cage as if it were a paraboloid of revolution with the vertex at the centre of a horizontal line joining the highest points of the inner borders of the first ribs and the base on the horizontal line joining the costophrenic angles. Its volume could therefore be expressed as $\frac{\pi}{2} a b^{2}$, with $a$ being the distance between the vertex and the base, and $b$ being half the length of the base. Appropriate subtractions were made for the right and left diaphragmatic domes, the heart, the vertebral bodies, the lung parenchyma, and pulmonary blood. The exact details of the formulae used to derive the volumes of each of the above can be found in the original paper.

(b) the ellipsoidal method of Barnhard et al. (1960).

This requires both PA and lateral chest films taken at full inspiration in the standard fashion. To compensate for the divergence of the $x$-ray beam, all linear measurements are reduced by $10 \%$.

Barnhard and his colleagues (1960) divided the thorax into a series of ellipses by means of horizonial sections. They expressed the area of each ellipse ${ }_{4}^{\pi} w e, w$ being the width of the chest in the plane of section, and $e$ its depth. Were the chest film to be divided into an infinitely large number of thin elliptical cross-sections, the volume could be obtained readily by integration. Practical considerations, however, make it necessary to limit the number of sections used. Calculations were made on the assumption that each section is an elliptical cylindroid.
For the purpose of this study, the chest was divided into five sections by six horizontal lines drawn on tracing paper placed over the PA film (Fig. 1). The lines were drawn as follows:

(i) below the inner borders of the highest ribs,

(ii) about $2.5 \mathrm{~cm}$. below i,

(iii) about $2 \cdot 5 \mathrm{~cm}$. below ii,

(iv) midway between iii and v,

(v) at the upper border of tise higher diaphragmatic segment,

(vi) between the lower limit of the costophrenic angles.

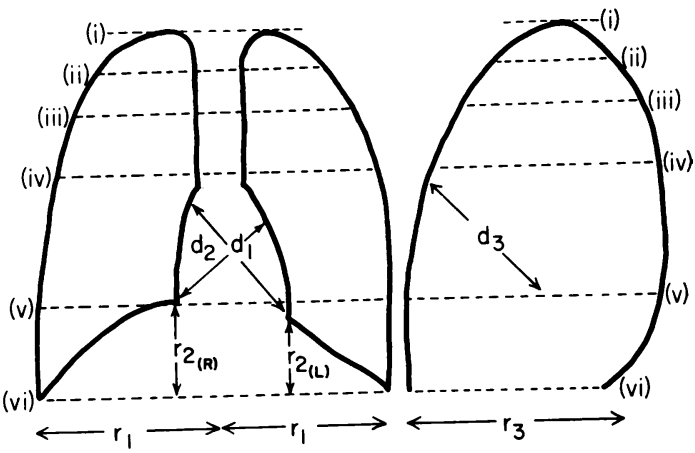

FIG. 1. Barnhard's method: measurements to be made on $P A$ and lateral films.

The PA and lateral films were aligned under the tracing paper so that line $v$ was at the same level on both films. The other horizontal lines were then extended over the lateral film. The total volume of these five elliptical cylindroids was taken as $\frac{\pi}{4} \underset{1}{5} w e h$, where $h$ was the sectional height, $w$ was measured between the inner borders of the ribs, and $e$ between the inner borders of the posterior ribs and the sternum (or a line drawn downward from the xiphoid process).

Each diaphragmatic segment was considered as oneeighth of an ellipsoid. The volume of the right was $\tilde{\pi}_{6} r_{1} r_{2} \quad r_{3}$ and that of the left $\frac{\pi}{6} r_{1} r_{2} \quad r_{3}$ where [R] [L] $r_{1}$ represented one-half of line vi over the PA film, $r_{2}$ and $r_{2}$ the heights of the right and left [R] [L]

segments and $r_{3}$ the length of line vi over the lateral film.

The heart was considered as a whole ellipsoid with a volume of $\pi_{6}^{\pi} d_{1} d_{2} d_{3}$. The line $d_{1}$ on the PA film was the greatest possible distance from the junction of the superior venous pedicle with the right atrium to the left heart border, usually as it meets the diaphragm. The line $d_{2}$ was drawn perpendicular to $d_{1}$ in such a position that it reflects the greatest distance between the right and left cardiac borders. On the lateral film and parallel to $d_{1}, d_{3}$ was the greatest distance between the anterior and posterior borders of the heart. 
T A B L E I

BLOOD VOLUME OF THE LUNGS (Vp) AS OBTAINED FROM THE HEIGHT

\begin{tabular}{|c|c|c|c|c|c|c|c|c|c|c|}
\hline $\begin{array}{c}\text { Height } \\
\text { (cm.) }\end{array}$ & & 1 & 2 & 3 & 4 & 5 & 6 & 7 & 8 & 9 \\
\hline $\begin{array}{l}160 \\
170 \\
180\end{array}$ & $\begin{array}{l}672 \\
816 \\
864\end{array}$ & $\begin{array}{l}700 \\
821 \\
868\end{array}$ & $\begin{array}{l}704 \\
826 \\
873\end{array}$ & $\begin{array}{l}733 \\
830 \\
878\end{array}$ & $\begin{array}{c}\text { Male } \\
738 \\
835 \\
883\end{array}$ & $\begin{array}{l}767 \\
840 \\
888\end{array}$ & $\begin{array}{l}771 \\
844 \\
892\end{array}$ & $\begin{array}{l}776 \\
850 \\
897\end{array}$ & $\begin{array}{l}806 \\
854 \\
902\end{array}$ & $\begin{array}{l}811 \\
859 \\
907\end{array}$ \\
\hline $\begin{array}{l}150 \\
160 \\
170\end{array}$ & $\begin{array}{l}517 \\
576 \\
612\end{array}$ & $\begin{array}{l}521 \\
580 \\
616\end{array}$ & $\begin{array}{l}524 \\
583 \\
619\end{array}$ & $\begin{array}{l}\quad F \\
551 \\
587 \\
622\end{array}$ & $\begin{array}{c}\text { Female } \\
554 \\
590 \\
626\end{array}$ & $\begin{array}{l}558 \\
594 \\
630\end{array}$ & $\begin{array}{l}561 \\
599 \\
634\end{array}$ & $\begin{array}{l}565 \\
601 \\
637\end{array}$ & $\begin{array}{l}568 \\
605 \\
641\end{array}$ & $\begin{array}{l}572 \\
608 \\
644\end{array}$ \\
\hline
\end{tabular}

The column on the left and the top row of figures denote the height in centimetres, e.g., a man $182 \mathrm{~cm}$. tall has a pulmonary blood volume of $873 \mathrm{ml}$.

The lung parenchyma was assumed to occupy $130 \mathrm{ml}$. The blood volume was derived from the data in the paper of Barnhard et al. (1960) (Table I).

TLC was then calculated in the following manner. The expression $\pi \underset{4}{\frac{5}{1}} w e h$ gives the volume of the whole thoracic cage. From this are subtracted:

(i) $\frac{\pi}{6} \quad r_{1} r_{2} \quad r_{3}$, the volume of the right dia[R]

phragmatic segment,

(ii) $\frac{\pi}{6} \quad r_{1} r_{2} \quad r_{3}$, the volume of the left dia[L]

phragmatic segment,

(iii) $\frac{\pi}{6} d_{1} d_{2} d_{3}$, the volume of the heart,

(iv) $130 \mathrm{ml}$., the volume of the lung parenchyma, and

(v) $\mathrm{V}_{\mathrm{p}} \mathrm{ml}$., the volume of the blood in the lungs. The volume remaining after the necessary subtractions represents the total lung capacity.

When it became apparent that certain methods were less reliable, we saw little point in persisting, and therefore abandoned them. In many instances, suitable chest films and the necessary determinations of lung capacity were available for inclusion in the study, although at the time the films were taken and the measurements made, it was not realized that they were going to be used for this purpose. Only recently have we started to do nitrogen washouts routinely. Consequently, many of the early patients did not have their lung volumes determined by this method. The chest films used in the study were routine PA and left lateral films. No special effort was made to obtain a maximal inspiratory effort. All the measurements necessary for the radiographic determinations of TLC were made by one person. Although three persons were involved in the plethysmographic determinations of lung volume, there was no reason to believe there was any substantial inter-observer error. In a few normal subjects the plethysmographic TLC was determined by all three observers with comparable values.

Basically, the study was designed to compare different methods of measuring TLC for several different groups of subjects. Difference distributions between the body plethysmograph and Barnhard's method were derived for each group of patients and the mean differences were tested against zero. Furthermore, the size of the variability of the differences was also considered. It became apparent that a high degree of positive linear association existed in the TLCs of each group as measured by the two methods. Accordingly, the degree and consistency of these relationships were determined by correlation and regression analyses.

All tests for statistical reliability were performed at the $95 \%$ confidence level.

\section{RESULTS}

We accepted the plethysmographic technique as the most accurate method of determining TLC and used it as the standard. The values obtained by the other methods were compared to those obtained by the body plethysmograph.

For the group of miners, there was substantial agreement between the plethysmographic values for TLC and those obtained by Barnhard's method (Fig. 2). On the other hand, when the values

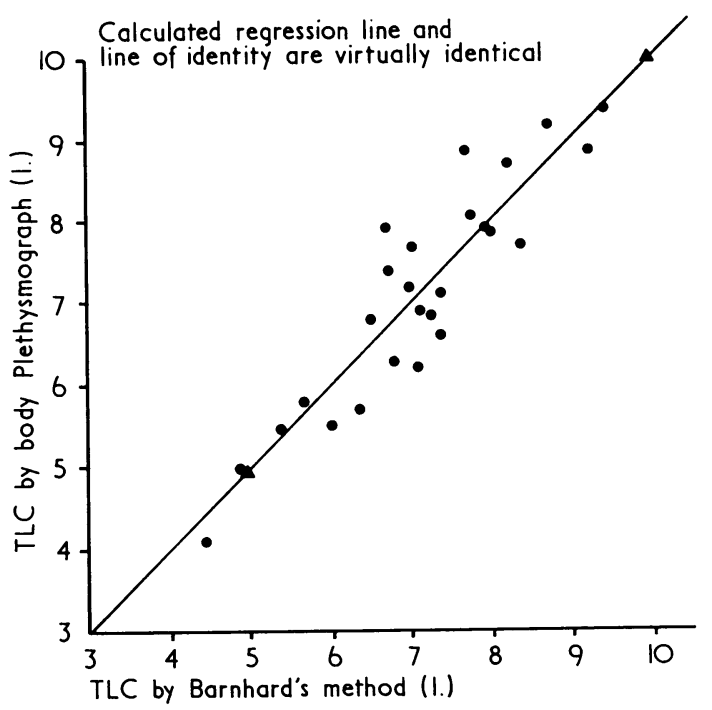

FIG. 2. Total lung capacity. Body plethysmograph v. Barnhard's method. Group 1 (miners, 26 subjects).

obtained by Kovach's method were compared with those obtained with the body plethysmograph, it can be seen there was often a marked disparity (Fig. 3). In 10 of the 26 miners, TLC was also determined by the nitrogen washout but was found, in general, to give lower values than either the body plethysmograph or Barnhard's method. This finding has been previously noted, especially 


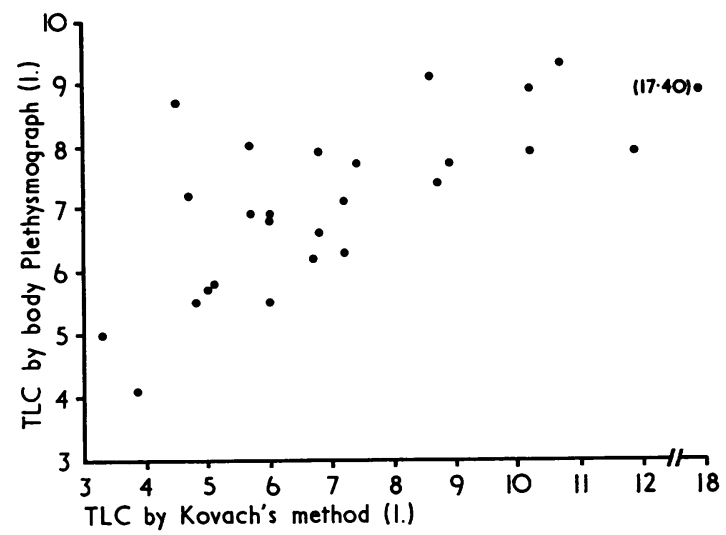

FIG. 3. Total lung capacity. Body plethysmograph v. Kovach's method. Group 1 (miners, 26 subjects).

in subjects with obstructive airway disease (Nicklaus, Watanabe, Mitchell, and Renzetti, 1967). We therefore decided that there was little point in persisting with this method since our investigations are concerned with subjects who are predominantly coal miners and who frequently have concomitant chronic bronchitis and emphysema.

When group 2 (normals) is considered, again it is apparent that there is a fairly close relationship between the TLC as measured by Barnhard's method and that obtained from the body plethysmograph (Fig. 4). A similar situation exists

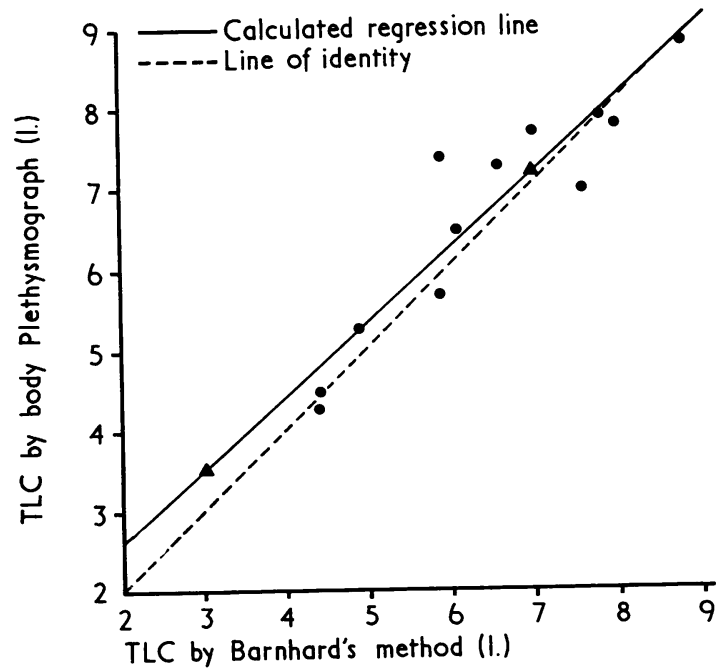

FIG. 4. Total lung capacity. Body plethysmograph v. Barnhard's method. Group 2 (normals, 12 subjects). in those subjects who have chest disease with and without pulmonary infiltration (groups 3 and 4); however, somewhat more variation was exhibited in group 4 (Figs 5 and 6).

In each patient group, the mean difference between the plethysmographic readings and those obtained by Barnhard's method was tested against

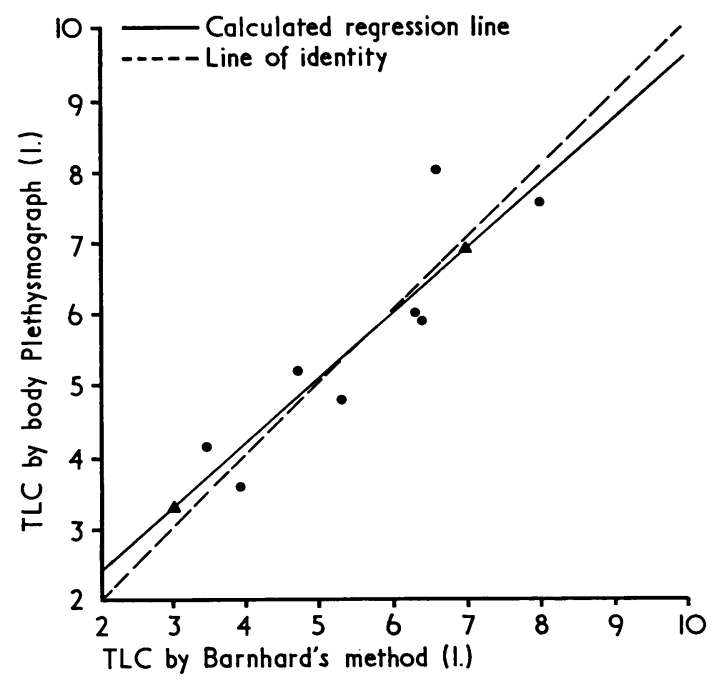

FIG. 5. Total lung capacity. Body plethysmograph v. Barnhard's method. Group 3 (chest disease without infiltration, 8 subjects).

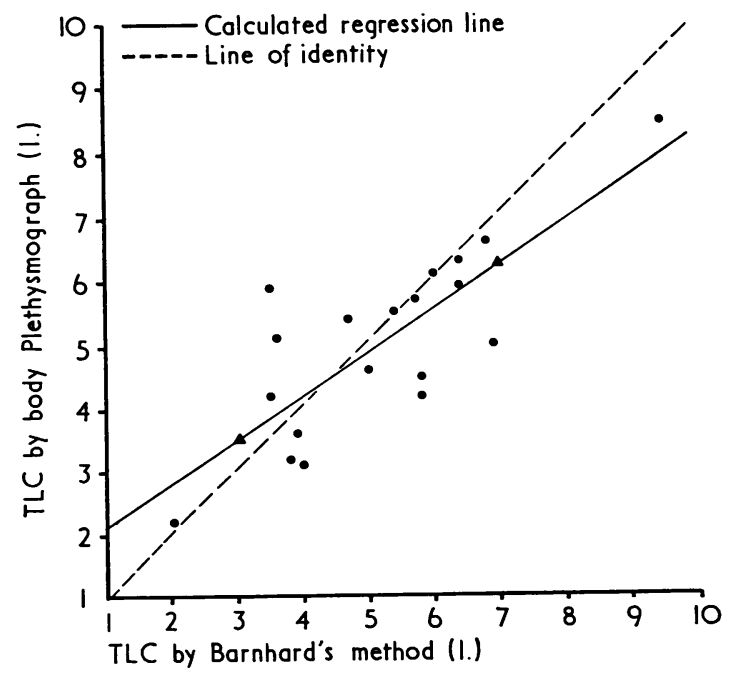

FIG. 6. Total lung capacity. Body plethysmograph v. Barnhard's method. Group 4 (chest disease with infiltration, 19 subjects). 
zero. None of the groups showed differences of significant magnitude. Although these results point to the general comparability of the two methods, it must be pointed out that the variability associated with the differences is appreciably larger in the subjects in group 4 than in any other group. This ranged from a low of 0.275 in the group of normals to a high of 1.064 in the group with chest disease with pulmonary infiltration (Table II). We

T A B L E I I

MEAN DIFFERENCE, VARIANCE AND ' $\mathrm{t}$ ' BETWEEN PLETHYSMOGRAPH READINGS AND MEASUREMENTS BY BARNARD'S ELLIPSOID FOR 4 PATIENT GROUPS

\begin{tabular}{l|c|c|c}
\hline Subjects & \multicolumn{2}{|c|}{ Plethysmograph minus Barnhard's Method } \\
\hline & $\begin{array}{c}\text { Mean } \\
\text { Difference }\end{array}$ & Variance & $\begin{array}{c}\text { Calculated } \\
\text { 't' Value }\end{array}$ \\
\hline $\begin{array}{c}\text { Group 1 } \\
\text { (coal miners) }\end{array}$ & -0.043 & 0.297 & -0.40 \\
$\begin{array}{c}\text { Group 2 } \\
\text { (normals) }\end{array}$ & 0.226 & 0.275 & 1.49 \\
$\begin{array}{c}\text { Group 3 } \\
\text { (chest disease } \\
\text { without } \\
\text { infiltration) } \\
\text { Group 4 } \\
\text { (chest disease } \\
\text { with infiltration) }\end{array}$ & -0.161 & 1.064 & -0.68 \\
\hline
\end{tabular}

therefore concluded that, regardless of the method or group, the TLC values would not differ significantly. Nonetheless, we have some qualms concerning the use of Barnhard's method in subjects who have demonstrable infiltration owing to the increased variability of the differences (Table II).

It should be mentioned at this point that a recent study (Reger and Jacobs, 1970) indicated that a single determination on a set of films using Barnhard's method will result in a relative error of between 5 and $6 \%$. The above-mentioned study was carried out using a randomly selected set of films without regard to the presence of pulmonary opacification or other lung pathology.

The results of the correlation analysis between the plethysmographic and Barnhard's method for each patient group showed varying degrees of linear association. Correlations ranged from 0.80 in group 4 to 0.93 in group 2 . Although it was demonstrated that no appreciable differences existed between the values obtained by Barnhard's method and the plethysmograph, it was still thought advisable to view the two methods in terms of regression equations. Least squares regression lines were determined for each of the four patient groups and tested against lines of ideal agreement. For group 4 (chest disease with infiltration), the hypothesis that the calculated slope equalled 1 was rejected. For the other groups, the slopes of the regression lines did equal 1. The coefficients $r, r^{2}, \alpha$ and $\beta$ are shown in Table III along with the results of testing the individual $\beta$ 's against 1 .

A special analysis was attempted on the group of patients with miscellaneous chest diseases

\section{T A B L E I I I}

RESULTS OF CORRELATION AND REGRESSION ANALYSIS (Plethysmographic $v$. Barnhard's Method)

\begin{tabular}{c|c|c|c|c|c}
\hline Subjects & $\begin{array}{c}\text { Correla- } \\
\text { tion } \\
\text { Coefficient }\end{array}$ & $\mathrm{r}^{2}$ & $\alpha^{1}$ & $\beta^{1}$ & $\begin{array}{c}\text { Test } \\
\beta=1\end{array}$ \\
\hline $\begin{array}{c}\text { Group 1 } \\
\text { (coal } \\
\text { miners) }\end{array}$ & 0.91 & 0.84 & -0.11 & 1.01 & Positive \\
$\begin{array}{c}\text { Group 2 } \\
\text { (normals) }\end{array}$ & 0.93 & 0.87 & 0.69 & 0.93 & Positive \\
$\begin{array}{c}\text { Group 3 } \\
\text { (chest } \\
\text { disease } \\
\text { without } \\
\text { infiltration) }\end{array}$ & 0.89 & 0.80 & 0.54 & 0.91 & Positive \\
$\begin{array}{c}\text { Group 4 } \\
\text { (chest } \\
\text { disease } \\
\text { with infil- } \\
\text { tration) }\end{array}$ & 0.80 & 0.64 & 1.49 & 0.68 & Negative \\
\hline
\end{tabular}

The constants $\alpha$ and $\beta$ are the intercept and slope respectively of the regression line. The intercept is the value of the mean of $y$ when $x$ is zero. The slope is the rate of change in the mean of $y$ for a unit change in $x$.

accompanied by infiltration (group 4). Its aim was to determine if the extent of the infiltration influenced the values obtained by Barnhard's method. Owing to the small number of observations, this did not prove possible.

\section{DISCUSSION}

For a pulmonary function test to be suitable for use in large-scale epidemiological studies, it must be simple, reasonably accurate, and easily repeatable and its performance preferably should require neither complex equipment nor sophisticated technical assistance that is not available in most settings. Spirometry offers a reasonably accurate way of assessing the amount of airways obstruction in a large group of subjects; on the other hand, the usual methods for the determination of lung volume require complicated and expensive equipment which is found only in hospital-based pulmonary function laboratories. Furthermore, two of the more commonly used methods, i.e., the nitrogen washout and helium equilibration technique, tend to underestimate the total thoracic gas, since both measure only that portion of the thoracic gas which is in free communication with the bronchial tree. The gas present in poorly ventilated areas, such as bullae and cysts, is not included in the TLC ascertained by these techniques. There would therefore seem to be a 
definite need for an accurate means of measuring lung volumes in epidemiological surveys.

We feel our data indicate that Barnhard's radiographic method of determining lung volume yields values that are very similar to, and probably interchangeable with, those obtained with the body plethysmograph. While it is fairly well accepted that the plethysmographic technique is the most accurate method of determining lung volumes, operation of the plethysmograph requires much technical skill and the instrument is expensive and difficult to use in the field. Our experience forces us to the conclusion that the results obtained by the 'occasional measurer', even if he is a physician, seldom compare favourably, with regard to reproducibility and spread, with those obtained by a physiologist who is constantly using the instrument. In contrast we found that the measurements necessary to derive TLC by Barnhard's method are easy to learn, require no electronic knowledge, and are associated with little in the way of interor intra-observer error (Reger and Jacobs, 1970). Moreover, a PA and lateral chest film is cheap, and can be easily and quickly taken in untrained subjects. The exception to this is found when the chest film shows either considerable infiltration or opacification, since in these circumstances Barnhard's method is likely to be less accurate.

An accurate radiographic method for determining lung volumes has great potential since it offers the means to compare RV/TLC ratios in different population groups. Furthermore, by repeating the studies at intervals, e.g., every five years, as in the National Coal Board's Pneumoconiosis Field Research Study (Rogan, Rae, and Walton, 1967), the change in the RV/TLC over a five-year period in different groups can be studied. Were the RV to increase more in certain groups, an increased incidence of airways obstruction might be inferred in these subjects. Doubts have been expressed in the past concerning the validity of radiographic techniques for determining lung volumes in the presence of obstructed airways. Our results indicate that neither simple pneumoconiosis nor obstructed airways influenced the accuracy of our determinations. The presence of pulmonary infiltration occasionally introduced a little more disparity between the TLC as determined by Barnhard's method and that determined by the plethysmograph, but even in these circumstances, the results were not too dissimilar.

\section{REFERENCES}

Aslett, E. A., Hart, P. D'Arcy, and McMichael, J. (1939). The lung volume and its subdivisions in normal males. Proc. roy. Soc. (Series B), 126, 502.

Barnhard, H. J., Pierce, J. A., Joyce, J. W., and Bates, J. H. (1960). Roentgenographic determination of total lung capacity. Amer. J. Med., 28, 51 .

Darling, R. C., Cournand, A., and Richards, D. W. Jr. (1940). Studies on the intrapulmonary mixing of gases. III. An open circuit method for measuring residual air. J. clin. Invest., 19, 609.

Davy, H. (J. Davy, Ed.) (1839). The Collected Works of Sir Humphry Davy, Vol. 3. Researches, chiefly concerning nitrous oxide, p. 242. Smith, Elder, London.

DuBois, A. B., Botelho, S. Y., Bedell, G. N., Marshall, R., and Comroe, J. H. (1956). A rapid plethysmographic method for measuring thoracic gas volume. J. clin. Invest., 35, 322.

Gaensler, E. A., and Wright, G. W. (1966). Evaluation of respiratory impairment. Arch. environm. Hith, 12, 146.

Hurtado, A., and Fray, W. W. (1933). Studies of total pulmonary capacity and its subdivision. II. Correlation with physical and radiological measurements. J. clin. Invest., 12, 807.

International Classification of Radiographs (1959). Occupational Safety and Health, 9, 63.

Kovach, J. C., Avedian, V., Morales, G., and Poulos, P. (1956). Lung compartment determination. J. thorac. Surg., 31, 452.

Nicklaus, T. M., Watanabe, S., Mitchell, M. M., and Renzetti, A.D. (1967). Roentgenologic, physiologic and structural estimations of the total lung capacity in normal and emphysematous subjects. Amer. J. Med., 42, 547.

Reger, R., and Jacobs, A. (1970). An analysis of components of variation in a radiological method for determining total lung. capacity. Arch. environm. Hlth, in press.

Rogan, J. M., Rae, S., and Walton, W. H. (1967). The National Coal Board's Pneumoconiosis Field Research. An interim review. In Inhaled Particles and Vapours II, ed. Davies, C. N., p. 493. Pergamon Press, Oxford and New York. 